\title{
Abordagem sobre as principais mudanças e cuidados no manejo odontológico frente ao novo Coronavírus
}

\author{
An approach concerning the main changes and care in dental management in the face of \\ Coronavirus \\ Enfoque sobre los principales cambios y cuidados en el manejo dental en relación con el \\ nuevo Coronavirus
}

Mariana Rezende Oliveira Bastos ${ }^{1 *}$, Nayara Rezende Oliveira Bastos ${ }^{1}$.

\section{RESUMO}

Objetivo: Abordar sobre as principais mudanças e cuidados no manejo odontológico frente ao enfrentamento do novo Coronavírus. Revisão bibliográfica: Os cirurgiões-dentistas foram considerados profissionais com grande risco de infecção cruzada pelo COVID-19, pois estão em contato direto com aerossóis, fluidos de pacientes e materiais contaminados. É necessária uma mudança no manejo odontológico, reforçando os equipamentos de proteção pessoal, limpeza e escolha de procedimentos que diminuam a chance de contágio viral. O profissional deve estar apto a reconhecer e selecionar os pacientes que necessitam de atendimento presencial, seguindo os protocolos recomendados pelos órgãos de saúde. São necessários mais estudos acerca do SARS-CoV-2, pois ainda se desconhece todo o seu comportamento. Considerações finais: Os profissionais da Odontologia devem seguir todas as mudanças propostas no manejo de pacientes em época do novo Coronavírus, reforçando a biossegurança, dando prioridade a procedimentos que não gerem aerossóis, triando pacientes, diminuindo assim o risco de infecção cruzada.

Palavras-chave: Covid-19, Coronavírus, Odontológico.

\section{ABSTRACT}

Objective: To address the main changes and care in dental management when facing the new Coronavirus. Literature review: Dental surgeons were considered professionals at high risk of cross-infection by Covid-19, as they are in direct contact with aerosols, patient fluids and contaminated materials. A change in dental management is necessary, reinforcing personal protective equipment, cleaning, and choosing procedures that reduce the chance of viral infection. The professional must be able to recognize and select patients who need face-to-face care, following the protocols recommended by health agencies. Further studies on SARS-CoV-2 are needed, as all their behavior is still unknown. Final considerations: Dental professionals must follow all the changes proposed in the management of patients at the time of the new Coronavirus, reinforcing biosafety, giving priority to procedures that do not generate aerosols, screening patients, thus reducing the risk of crossinfection.

Keywords: Covid-19, Coronavirus, Dental.

\section{RESUMEN}

Objetivo: Abordar los principales cambios y cuidados en el manejo dental ante el nuevo Coronavirus. Revisión bibliográfica: Los cirujanos dentistas fueron considerados profesionales con alto riesgo de infección cruzada por Covid-19, ya que están en contacto directo con aerosoles, fluidos de pacientes y materiales contaminados. Es necesario un cambio en el manejo dental, reforzando el equipo de protección personal, limpiando y eligiendo procedimientos que reduzcan la posibilidad de infección viral. El profesional debe ser capaz de reconocer y seleccionar a los pacientes que necesiten atención presencial, siguiendo los protocolos recomendados por las agencias de salud. Se necesitan más estudios sobre el SARS-CoV-2, ya que aún se desconoce todo su comportamiento. Consideraciones finales: Los profesionales dentales deben seguir todos los cambios propuestos en el manejo de los pacientes en la época del nuevo Coronavirus, reforzando la bioseguridad, dando prioridad a los procedimientos que no generan aerosoles, ordenando a los pacientes, reduciendo así el riesgo de infección cruzada.

Palabras clave: Covid-19, Coronavirus, Dental.

1Universidade Federal de Juiz de Fora (UFJF), Juiz de Fora - MG. *E-mail: mari.rezende93@hotmail.com

SUBMETIDO EM: $8 / 2020$

ACEITO EM: 9/2020

PUBLICADO EM: 9/2020 


\section{INTRODUÇÃO}

Em 11 de março de 2020, a Organização Mundial da Saúde decretou estado de pandemia, causada por um novo tipo de Coronavírus, denominado SARS-CoV-2 (Síndrome Respiratória Aguda Grave Coronavírus 2), causador da Covid-19 (DE OLIVEIRA JJM, et al., 2020; SOUZA RCC, et al., 2020). A partir desse momento, medidas foram estabelecidas, impactando de forma significativa a vida das pessoas de todo 0 mundo.

O Coronavírus pertence à família Coronavidae e são divididos em quatro grupos (alfa, beta, gamma e delta). Os tipos alfa e beta atingem principalmente a função respiratória, gastrointestinal e nervosa central de mamíferos e humanos. Já os tipos gamma e delta têm como alvo principal as aves (FINI MB, 2020; TUÑAS ITC, et al., 2020; GUIÑES CM, 2020).

O primeiro caso relatado pela OMS aconteceu na cidade de Wuhan, localizada na China e rapidamente se espalhou ao redor do mundo. Ainda não se sabe como o vírus se originou, porém foi relatado que ele se liga a um receptor chamado ACE-2 de células humanas e através de estudos, constatou-se que a língua possui maior expressão do mesmo, o que torna a cavidade oral uma via de alto risco de infecção (DE OLIVEIRA JJM, et al., 2020).

A maioria das pessoas infectadas que desenvolvem sintomas apresentam um quadro leve da doença. A Comissão Nacional de Saúde da China apontou que os casos graves variam de 15 a $25 \%$. O paciente pode se apresentar de forma sintomática, tendo febre, tosse, falta de ar, podendo chegar a um quadro de pneumonia e evoluir para a morte, ou se apresentar de forma assintomática (FINI MB, 2020). Existe um grupo de pessoas que são mais susceptíveis a desenvolverem complicações se infectadas. É o chamado "grupo de risco", que inclui pacientes com doenças cardiovasculares, hipertensão arterial, diabetes mellitus, doenças que afetam o sistema imunológico e idosos (DE OLIVEIRA JJM, et al., 2020; FINI MB, 2020).

O novo Coronavírus é considerado muito transmissível, podendo infectar através de espirros, tosses, exposição das mucosas ocular, nasal e oral com gotículas/aerossóis contendo SARS-CoV-2 oriundos de secreções de vias aéreas, saliva ou sangue. Os pacientes sintomáticos são considerados as primeiras vias de transmissão, porém já se sabe que os assintomáticos e os que estão no período de incubação, que pode durar 14 dias, também são portadores do vírus. A alta umidade e temperatura diminuem a sua transmissão, por isso acredita-se que no verão e em estações de chuva haverá uma diminuição da Covid-19.

O SARS-CoV-2 é um vírus descoberto recentemente, que necessita de maiores investigações quanto ao seu comportamento (FINI MB 2020; SOUZA RCC, et al., 2020; DE OLIVEIRA JJM, et al., 2020; SEPÚLVEDA VC, et al., 2020; TUÑAS ITC, et al., 2020; ABANTO J, et al., 2020). Até o presente momento, ainda não existe um tratamento eficaz e seguro para o Covid-19. É necessário controlar a fonte de infecção e transmissão, através de medidas como detecção precoce de pessoas infectadas, quarentena e assistência aos pacientes (ABANTO J, et al., 2020).

Os tratamentos dentários produzem aerossóis que apresentam altos riscos para o Cirurgião-dentista, pelo fato do atendimento ser feito face a face, tendo contato íntimo com fluidos de diversos pacientes durante todo o dia (DE OLIVEIRA JJM, et al., 2020; TUÑAS ITC, et al., 2020; MARTINS-JUNIOR PA, et al., 2020; GONZÁLEZ QD e SANTOS-LÓPEZ M, 2020).

O objetivo dessa revisão foi abordar todas as mudanças e cuidados no manejo odontológico frente ao novo Coronavírus, alertando, orientando e informando não só os Cirurgiões-dentistas, mas também as equipes de saúde e os próprios pacientes, evitando o aumento das infecções cruzadas e a disseminação da Covid-19.

\section{REVISÃO BIBLIOGRÁFICA}

\section{A importância dos cirurgiões-dentistas}

Os profissionais de saúde, principalmente os Cirurgiões-dentistas, são consideradas pessoas que têm grande risco de infecção cruzada pelo novo Coronavírus. Isso se justifica pela íntima exposição com fluidos como saliva e sangue, além de produtos resultantes de aerossóis e instrumentos cortantes manuais 
contaminados (FINI MB, 2020; SOUZA RCC, et al., 2020; DE OLIVEIRA JJM, et al., 2020; SEPÚLVEDA VC, et al., 2020; TUÑAS ITC, et al., 2020; MARTINS-JUNIOR PA, et al., 2020; ABANTO J, et al., 2020; GONZÁLEZ QD e SANTOS- LOPEZ M, 2020; GUIÑES CM, 2020; VARGAS-BURATOVIC JP, et al., 2020; CARRER FCA, et al., 2020). Apesar dos resultados equivalentes entre todos os autores dessa revisão, ainda não há evidência científica que suporte esse fato (DE OLIVEIRA JJM, et al., 2020).

A American Dental Association decretou em 16 de Março de 2020 que os Cirurgiões-dentistas deveriam adiar os tratamentos eletivos, atendendo somente casos de urgência e emergência (FINI MB, 2020). Esse decreto, com o passar dos meses foi mudando de acordo com cada país e estado. No Brasil, as orientações da Agência Nacional de Vigilância Sanitária (ANVISA), com o apoio do Conselho Federal de Odontologia orientou sobre procedimentos que podem gerar aerossóis durante o atendimento, devendo suspendê-los nos casos suspeitos e confirmados da infecção de Covid-19 (SOUZA RCC, et al., 2020).

\section{Tratamento da Covid-19}

Até o presente momento, ainda não existe uma vacina segura e eficaz contra o novo Coronavírus. Sabese de ensaios clínicos e estudos feitos na Rússia, Estados Unidos e China, porém ainda não são vistos como tratamentos efetivos pela Organização Mundial de Saúde.

\section{O impacto do novo Coronavírus no manejo odontológico}

É importante que o profissional odontológico saiba identificar os casos suspeitos da Covid-19. Em um primeiro momento, se deve fazer a tele-triagem dos pacientes, para reconhecer esses casos e analisar a necessidade de consulta presencial para tratamento. A triagem é feita através de perguntas específicas, que incluem se o paciente teve febre, desenvolveu algum problema respiratório, viajou para algum lugar com notificação da doença, teve contato com pessoas confirmadas com Covid-19 nos últimos 14 dias, esteve presente em aglomerações com pessoas desconhecidas ou se apresentou algum outro sintoma característico da doença.

Após essa etapa, um rastreio quanto a patologia apresentada deve ser feito (FINI MB, 2020; TUNÃS ITC, et al., 2020; DE OLIVEIRA JJM, et al., 2020; GONZÁLEZ QD e SANTOS-LÓPEZ M, 2020; ABANTO J, et al., 2020). O paciente responde se há presença de dor, edema, traumatismos dentários, entre outros. Recomenda-se também o uso de imagens, fotos e outros exames que permitam auxiliar no diagnóstico. Durante o período de isolamento, a recomendação era que o tratamento odontológico fosse realizado exclusivamente em pacientes que apresentam casos de urgência e emergência, apesar de que nos últimos meses, vários estados do Brasil já realizam procedimentos eletivos.

As emergências odontológicas são caracterizadas por colocarem em risco a vida dos pacientes que precisam de tratamento imediato, tais como celulite facial com edema intra e extra-oral e traumas que comprometem as vias aéreas, sangramento descontrolado, entre outros. Já as urgências odontológicas são caracterizadas por situações de dor e infecções graves, tais como periocoronarite, pulpite irreversível severa, abscesso dento alveolar localizado, alveolite, traumatismo dentário com luxação ou avulsão, biópsia, fratura dentária dolorosa ou preparação dentária prévia a procedimentos médicos.

Emergências odontológicas devem ser atendidas somente em hospitais e nunca no consultório. Caso seja possível, deve-se realizar primeiramente um tratamento sintomático com o uso de analgésicos e antibióticos e acompanhar o paciente até que 0 isolamento seja suspenso e outras medidas terapêuticas possam ser tomadas (ABANTO J, et al., 2020; SEPÚLVEDA VC, et al., 2020; FINI MB, 2020).

O British Medical Journal indicou acetaminofeno no lugar do ibuprofeno para pacientes infectados, pois acredita-se que o ibuprofeno interfere na função do sistema imunológico (FINI MB, 2020). Já o Comitê de Avaliação de Riscos de Farmacovigilância da Agência Europeia de Medicamentos recomendou não usar o Cetoprofeno, pois pode mascarar os sintomas da infecção (GONZÁLEZ QD e SANTOS-LÓPEZ M, 2020).

Logo após a triagem, identificação da patologia e da necessidade de atendimento no consultório, os pacientes presenciais são selecionados e orientados para a consulta. O Cirurgião-dentista deve medir a temperatura dos pacientes antes de iniciar a consulta. Se ele respondeu afirmativo para qualquer uma das perguntas presentes na triagem e apresentar uma temperatura maior que $37,3^{\circ} \mathrm{C}$, o profissional deve adverti- 
lo sobre um possível contágio, além de encaminhá-lo para uma unidade de saúde competente. Se a temperatura do paciente for menor que $37,3^{\circ} \mathrm{C}$, ele deverá retornar ao consultório após 14 dias, salvo em casos de urgência. Para respostas negativas ao questionário e temperatura maior que $37,3^{\circ} \mathrm{C}$, o paciente deverá também retornar após 14 dias, com exceção aos casos de urgência. Se sua temperatura for menor que $37,3^{\circ} \mathrm{C}$, o tratamento odontológico será viável, com todos os cuidados recomendados (TUÑAS ICT, et al., 2020; GUIÑES CM, 2020).

\section{A prevenção da infecção cruzada nos consultórios odontológicos}

Uma série de medidas preventivas devem ser adotadas para minimizar e controlar a transmissão cruzada nos consultórios. Tudo se inicia com a lavagem das mãos, etapa considerada mais crítica e importante pela literatura abordada. Deve ser feita por aproximadamente 20 a 30 segundos, antes e após o atendimento odontológico.

O álcool 70\% também pode ser usado nessa etapa, por no mínimo 20 segundos. Para se ter sucesso, recomenda-se a retirada de todos os acessórios, como relógios, pulseiras e anéis, além dos brincos e colares, pois são uma fonte potencial de infecção (TUÑAS ITC, et al., 2020; VARGAS-BURATOVIC JP, et al., 2020; GONZÁLEZ QD e SANTOS-LÓPEZ M, 2020; FINI MB, 2020; SEPÚLVEDA VC, et al., 2020; GUIÑES CM, 2020).

Guiñes CM (2020); recomendou a lavagem das mãos por 30 segundos ou mais e se não for possível, utilizar álcool em gel também na concentração de $90 \%$. Ela deve ser feita depois de tocar superfícies e equipos infectados ou algum tipo de fluido. Abanto J; et al. (2020); considerou a higienização das mãos com solução de clorexidina e depois com álcool em gel $70 \%$.

Todas as pessoas que se direcionarem aos centros de saúde necessitam obrigatoriamente usar máscara de proteção. Em relação aos Cirurgiões-dentistas, o Equipamento de Proteção Individual (EPI) deve ser completo, pois esses profissionais têm contato direto com fluidos, aerossóis e pacientes. Não se deve comer e beber no consultório e colocar objetos pessoais em regiões próximas ao local do tratamento.

As máscaras utilizadas, segundo a OMS e American Dental Association, devem ser a do tipo N95 ou FFP2. Além disso, deve-se usar protetores oculares, máscaras faciais, gorros descartáveis, propés e jalecos, que poderão ser descartáveis ou não (GONZÁLEZ QD e SANTOS-LÓPEZ M, 2020; FINI MB, 2020; SEPÚLVEDA VC, et al., 2020). O uso da máscara FFP92 não deve exceder 4 horas (GUIÑES CM, 2020).

Abanto J; et al. (2020); indicaram uma diferença entre as máscaras usadas em procedimentos que produzem ou não aerossóis. Nos que produzem, deve-se usar máscaras n95, FFP2 ou FF93, sendo que adicionalmente pode-se usar uma máscara convencional sobre a n95, para permitir que o respirador seja reutilizado. Já para procedimentos que não produzem aerossóis, somente a máscara cirúrgica foi apontada. A máscara n95 mostrou uma vida útil de 8 horas. Foi aprovado o seu uso por longo prazo, desde que não esteja contaminada, suja ou danificada.

Muitos estudos apontaram que bochechos antes dos procedimentos diminuem a quantidade de microorganismos nas superfícies e no ambiente. Foi indicado o uso de Peróxido de Hidrogênio a 1\% e lodopovidona a 0,2\%, pois acredita-se que o vírus é susceptível a oxidação desses produtos (TUÑAS ITC, et al., 2020; SEPÚLVEDA VC, et al., 2020; ABANTO J, et al., 2020; GONZÁLES QD e SANTOS-LÓPEZ M, 2020; VARGAS-BURATOVIC JP, et al., 2020; GUIÑES CM, 2020).

Tuñas ITC; et al. (2020); não recomendaram o uso da Clorexidina 0,12\%, pois ela não mostrou eficácia na prevenção da transmissão do vírus da Covid-19. Porém, alguns estudos apontaram uma redução média de $68,94 \%$ das unidades formadoras de colônia em aerossóis dentais, além de ser eficiente contra alguns vírus infecciosos, como o HIV, HSV e HBV (FINI MB, 2020).

$\mathrm{O}$ isolamento absoluto deve ser realizado em procedimentos como tratamentos de canal, restaurações e qualquer outro tipo que envolvam fluidos corporais, mantendo o campo seco e limpo. Em relação aos cuidados contra o novo Coronavírus, o seu uso também foi recomendado, pois ele reduz a produção de aerossóis contaminados por saliva e sangue formados pela seringa tríplice, motor de alta rotação e ultrassom. Em casos 
que $o$ isolamento absoluto não possa ser empregado, optou-se pela remoção de cárie através de técnicas manuais atraumáticas, raspagem manual ou remoção química (TUÑAS ITC, et al., 2020; ABANTO J, et al., 2020; GUIÑES CM, 2020; VARGAS-BURATOVIC JP, et al., 2020).

As peças de mão, como motores de alta e baixa rotação, devem ser autoclavadas e recomenda-se a utilização das que possuem válvulas de antirretração ou antirrefluxo (FINI MB, 2020; TUÑAS ITC, et al., 2020, ABANTO J, et al., 2020; DE OLIVEIRA JJM, et al., 2020). Antes, é necessário fazer a limpeza das peças com água e sabão durante 2 minutos.

Relacionado aos procedimentos que envolvam anestesias e suturas, a literatura revisada apresentou o seguinte resultado: deve-se considerar a utilização de anestesias tronculares e um complemento infiltrativo na primeira instância, a fim de evitar a necessidade de reforços anestésicos durante o procedimento e risco de contaminação do meio. As suturas recomendadas são as com material reabsorvível, evitando a necessidade de outra consulta para a sua retirada. Nas cirurgias, a irrigação dos alvéolos e água dos motores deve ser feita com sugadores de alta potência (GONZÁLEZ QD e SANTOS-LÓPEZ M, 2020; VARGASBURATOVIC JP, et al., 2020; GUIÑES CM, 2020)

A ANVISA informou através de uma nota técnica que os procedimentos de anestesia eletivos devem ser suspensos temporariamente durante a fase da pandemia. Já a Sociedade Brasileira de Anestesiologia recomendou que os procedimentos de anestesia e sedação sejam feitos em circuitos fechados de aspiração e que os pacientes com suspeita de Covid-19 sejam anestesiados com um aparelho individual e específico.

Na sedação, deve-se considerar que o uso de óxido nitroso e oxigênio provoca produção de aerossóis e pode atingir até 2 metros do raio que a máscara é instalada, contaminando diretamente o profissional e a equipe, além dos equipamentos. A sedação parenteral sem oxigênio suplementar não produziria os aerossóis, se tornando uma alternativa mais segura. Porém, constatou-se que a sedação se configura em mais um risco de disseminação do novo Coronavírus. Não foi recomendado também a realizar com medicamentos, devido a necessidade de se ter remédios disponíveis e de medidas de suporte de vida que envolvem a manipulação das vias aéreas e o uso de rede hospitalar (SOUZA RCC, et al., 2020).

Uma importante etapa antes e após o atendimento odontológico é a desinfecção completa de superfícies, materiais e objetos do consultório, além de todo o ambiente de atendimento, pois há estudos que mostraram que 0 novo Coronavírus pode sobreviver de 2 a 9 dias nesses lugares. As superfícies podem ser contaminadas por aerossóis e por contato direto, porém alguns produtos específicos têm se mostrado eficazes na sua limpeza. Hipoclorito de Sódio a 1\%, Peróxido de Hidrogênio a 0,5\% e Álcool a 70\% foram os mais indicados (GONZÁLEZ QD e SANTOS-LÓPEZ M, 2020; TUÑAS ITC, et al., 2020; SEPÚLVEDA VC, et al., 2020; FINI MB, 2020; DE OLIVEIRA JJM, et al., 2020).

Não se recomendou o uso de Clorexidina devido à baixa efetividade para a eliminação do vírus (SEPÚLVEDA VC, et al., 2020). Uma outra forma de limpeza foi a desinfecção por UV duas vezes ao dia, durante meia hora e do box com $2100 \mathrm{mg} / \mathrm{L}$ de cloro, sendo que em casos suspeitos deve-se utilizar $5000 \mathrm{mg} / \mathrm{L}$, incluindo o piso. O instrumental contaminado deve ser lavado e esfregado com sabonete líquido e cloro. Após a secagem, esterilizado (ABANTO J, et al., 2020). Cada superfície deverá ter uma barreira de proteção, que precisa ser trocada a cada paciente. As salas de espera não devem ter revistas, jornais ou folhetos (TUÑAS ITC, et al., 2020).

A área de tratamento e diagnóstico odontológicos deve ter boa ventilação, abrindo a janela por no mínimo 3 vezes ao dia durante meia hora cada. $O$ tratamento a 4 mãos foi indicado como mais eficiente, mas somente devem permanecer no consultório o paciente e os dois profissionais (Cirurgião-dentista e assistente). É permitido no máximo um acompanhante no caso de crianças e pacientes com necessidades especiais. Devese evitar saídas do espaço de trabalho durante o tratamento e, ao seu final, desinfetar o espaço aéreo com desinfetante em aerossol e aguardar 2 minutos para abrir a porta. Os materiais biológicos deverão ser descartados nos recipientes adequados, com etiquetas indicadoras e o paciente deverá lavar as mãos e 0 rosto antes de se retirar (ABANTO J, et al., 2020; FINI MB, 2020).

Ao final das consultas presenciais, se algum profissional ou membro da equipe apresentar uma temperatura corporal superior a 37,3\%, ele deverá ser afastado durante o período de 14 dias (TUÑAS ITC, et al., 2020). 
Todas as pessoas têm que ser vistas e tratadas como potenciais fontes de transmissão do SARS-CoV-2, pois ainda se afirma que os testes disponíveis são insuficientes, além da presença de pacientes assintomáticos ou em fase inicial da doença, considerados também transmissores. Deve-se ter o mínimo de contato do paciente com a equipe odontológica, secretárias e faxineiras. Os horários para atendimento de cada paciente precisam ser pré-estabelecidos, mantendo sempre a distância de 2 metros entre cada um (ABANTO J, et al., 2020).

Procedimentos odontológicos alternativos e eficazes podem ser adotados para minimizar a produção de aerossóis. Caso essa produção seja necessária, orienta-se a realização das consultas em uma unidade de isolamento respiratório com pressão negativa e filtro HEPA. Se a unidade não estiver disponível, consultórios com portas fechadas devem ser usados (TUÑAS ITC, et al., 2020).

\section{Protocolos clínicos para controle dos aerossóis}

Algumas medidas especiais podem ser tomadas para evitar o risco de transmissão cruzada do SARSCoV-2. Em casos de inflamação pulpar, seja reversível como irreversível, indicou-se realizar uma trepanação de urgência com instrumentos manuais. Caso isso não seja possível, uma alternativa seria o uso de motores de baixa rotação, com isolamento absoluto e aspiração potente (SEPÚLVEDA VC, et al., 2020).

As cáries dentárias podem ser tratadas de diversas formas as quais não precisam de peças de mão e produção de aerossóis. $O$ tratamento restaurador atraumático foi uma ótima alternativa apontada. Pode ser feito com instrumentos manuais cortantes, aplicação de CIV de alta viscosidade e proteção com vaselina sólida. A técnica de Hall também mostrou eficiência, com o recobrimento do dente com coroas de aço e ainda a remoção seletiva de tecido cariado, feito com colheres de dentina e restauração com resina composta, compômero ou CIV modificado por resina (ABANTO J, et al., 2020; SEPÚLVEDA VC, et al., 2020).

O uso de agentes químicos-mecânicos compostos por aminoácidos e hipoclorito de sódio para se remover cáries cavitadas e profundas se apresentou como outra boa alternativa, pois além de não utilizar instrumentos rotatórios, há uma menor percepção de dor pelos pacientes, apesar do tempo operatório ser maior (SEPÚLVEDA VC, et al., 2020).

Nos casos de urgências periodontais, como gengivites e periodontites úlcero-necrosantes, se o estado da doença não regredir com o uso de AINES e antibióticos como Amoxicilina e Metronidazol, deve-se fazer raspagem com curetas manuais em conjunto com irrigação abundante com soro fisiológico, peróxido de hidrogênio ou clorexidina. O uso de ultrassons e jatos de bicarbonatos não foi recomendado, pois produzem grande quantidade de aerossóis. Em casos de traumatismos dentoalveolares, optar se possível pelo uso de resinas fluidas para evitar a necessidade de polimento com motores e a utilização de seringa tríplice (SEPÚLVEDA VC, et al., 2020).

\section{CONSIDERAÇÕES FINAIS}

Os Cirurgiões-dentistas são profissionais da saúde que possuem um contato face a face com os pacientes nos procedimentos odontológicos. Devido a essa exposição e contato com fluidos, aerossóis e equipamentos contaminados, o risco de infecção cruzada foi considerado grande na literatura abordada. Existem hoje em dia várias recomendações que visam diminuir esse índice e proteger todas as pessoas envolvidas no tratamento dentário. Porém, desafios quanto ao enfrentamento do novo Coronavírus ainda serão relatados e cabe a cada profissional se adequar a essa nova realidade, desempenhando um importante papel no controle e prevenção da Covid-19 e respeitando todas as orientações propostas pelos órgãos de saúde.

\section{REFERÊNCIAS}

1. ABANTO J, et al. Tratamento da doença cárie em época de COVID-19: Protocolos clínicos para controle dos aerossóis. Revista de Odontopediatria Latinoamericana. Volume 10, N 2, 2020.

2. ABANTO J, et al. Rota de atenção para procedimentos na Odontopediatria durante o período de isolamento ou quarentena da pandemia COVID-19. Revista de Odontopediatria Latinoamericana. Volume 10, N² 2, 2020.

3. AMERICAN DENTAL ASSOCIATION. Coronavírus frequently asked questions. ADA Center for professional Success, 2020. 
4. CARRER FCA, et al. A COVID-19 na América Latina e suas repercussões para a odontologia. Rev Panam Salud Publica. 2020;44:e66.

5. DA SILVA ROC, et al. Protocolos de atendimento odontológico durante a pandemia de COVID-19 nos países do MERCOSUL: similaridades e discrepâncias. Vigil. sanit. debate 2020;8(3):86-93.

6. DE OLIVEIRA JJM, et al. O impacto do coronavírus (covid-19) na prática odontológica: desafios e métodos de prevenção. Revista Eletrônica Acervo Saúde/Eletronic Journal Colletion Health, Vol.Esp.46, Edição 3487, 2020.

7. FINI MG. O que dentistas precisam saber sobre a COVID-19. Oncologia Oral. Volume 105, 2020.

8. FRANCO ABG, et al. Atendimento odontológico em UTI's na presença de COVID-19. InterAm J Med Health 2020;3:e202003004.

9. GOMES GGC, et al. Perfil epidemiológico da Nova Doença Infecciosa do Coronavírus - COVID-19 (Sars-Cov-2) no mundo: Estudo descritivo, janeiro-junho de 2020. Braz. J. Hea. Rev., Curitiba, v. 3, n. 4, p. 7993-8007 jul./aug.. 2020.

10. GONZÁLEZ QD e SANTOS-LÓPEZ M. Medidas Preventivas y Consideraciones para la Práctica de Cirugía Oral durante COVID-19. Int. J. Odontostomat. 14(3):338-341, 2020.

11. GUIÑES CM. Impacto del COVID-19 (SARS-CoV-2) a Nivel Mundial, Implicancias y Medidas Preventivas en la Práctica Dental y sus Consecuencias Psicológicas en los Pacientes. Int. J. Odontostomat., 14(3):271-278, 2020.

12. MACHADO GM, et al. Biossegurança e retorno das atividades em odontologia: aspectos relevantes para enfrentamento de covid-19. Stomatos, Vol. 26, N 50, Jan./Jun. 2020.

13. MARTINS-JÚNIOR PA, et al. COVID-19: Arquivos para a Odontologia. Arquivos em Odontologia, Belo Horizonte, 56: e00, 2020.

14. ORGANIZAÇÃO MUNDIAL DA SAÚDE. Doença de Coronavírus 2019 (COVID-19). 2020. Relatório de situação-45. Genebra, Suíça: Organização Mundial da Saúde.

15. SÁNCHEZ-VARGAS LO e POZOS-GUILLÉN A. El coronavirus. ¿Estábamos preparados?. Rev ADM. 2020;77(2):8083. doi:10.35366/93099.

16. SEPÚLVEDA VC, et al. Consideraciones en la atención odontológica de urgencia en contexto de coronavírus COVID19 (SARS-CoV-2). Int. J. Odontostomat., 14 (3): 279-284, 2020.

17. SOUZA RCC, et al. Precauções e Recomendações sobre Sedação Odontológica durante a Pandemia de COVID-19. Revista Brasileira de Odontologia. Vol 77, edição 1788, 2020.

18. TEICHERT-FILHO R, et al. Dispositivo de proteção para reduzir a dispersão de aerossóis no tratamento odontológico em tempos de pandemia de COVID-19. Int Endod J. 2020.

19. TUÑAS ITC, et al. Doença pelo Coronavírus 2019 (COVID-19): Uma abordagem preventiva para Odontologia. Revista Brasileira de Odontologia, Rio de Janeiro, 2020; 77: 1-6.

20. VARGAS-BURATOVIC JP, et al. Recomendaciones odontológicas en la pandemia COVID-19: revisión narrativa. Medwave 2020;20(5): e7916. 